\title{
Evolução setorial do emprego nas regiões chilenas no período de 2007-2009
}

\author{
Development sector employment in chilean regions in the years 2007-2009
}

\section{Évolutions sectorielles de l'emploi dans les régions chiliennes dans les années 2007-2009}

\author{
Evolución sectorial del empleo en las regiones chilenas entre 2007 y 2009 \\ Daniela Peres Cardozo* \\ (daniyellaperes@hotmail.com) \\ Gilson Batista de Oliveira* \\ (gilson.oliveira@unila.edu.br)
}

Recebido em 07/04/2015, revisado e aprovado em 23/07/2015; aceito em 20/11/2015

DOI: http:// dx.doi.org/10.20435/1518-70122016103

\begin{abstract}
Resumo: Este artigo tem como objetivo analisar a variação setorial e regional do emprego chileno entre os anos de 2007 e 2009. Para tanto, utilizou-se a metodologia shift-share (estrutural-diferencial), uma ferramenta de dados estatísticos que possibilita identificar os distintos fatores relacionado à variação do emprego, variação essa atribuída a aspectos estruturais e diferenciais. Setorialmente, os resultados apresentados indicam que os setores exportadores foram os que tiveram os piores desempenhos, sendo o componente estrutural explicativo para o fato. Em relação às regiões, Tarapacá, Coquimbo, Valparaíso, Maule, Araucanía, Aysen, Magallanes y la Antártica Chilena e a Região Metropolitana apresentaram as maiores taxa de crescimento na criação de emprego, enquanto as demais ficaram abaixo da média nacional. Desse modo, o presente trabalho ressalta a importância da aplicação e leitura da análise regional para avaliar, bem como para estabelecer uma agenda de políticas regionais e nacional após diagnosticar suas deficiências setoriais.
\end{abstract}

Palavras-chave: Análise regional. Emprego. Chile.

Abstract: This article aims to analyze the variation of the sector and regional Chilean employment between 2007 and 2009. The development of this article used the shift-share methodology (structural-differential), a statistical tool that helps identify the different factors related to change in employment, change to structural and differential aspects by comparing each region with the national performance. By sector, the results indicate that the export sectors were those who had the worst performance. Concerning in the regions, Tarapaca, Coquimbo, Valparaiso, Maule, Araucania, Aysen, Magallanes y la Antartica Chilena and the metropolitan area had the highest growth rate in job creation. Thus, this work emphasizes the importance of applying and reading the regional analysis to evaluate and establish an agenda of regional and national policies after diagnosing their sectoral deficiencies.

Key words: Regional analysis. Employment. Chile.

Résumé: Cet article analyse la variation sectorielle et régionale de l'emploi du Chili dans les années 2007 et 2009. À cette fin, nous avons utilisé la méthode 'shift-share', un outil de statistiques de réseau qui permet l'identification des différents facteurs liée à la variation de l'emploi, cette variation est attribuable à aspects structurels et différentielles. Par secteur, les résultats indiquent que les secteurs d'exportation étaient ceux qui avaient les pires performances, avec le composant structurel explicative sur le fait. En ce qui concerne les régions, Tarapaca, Coquimbo, Valparaíso, Maule, Araucania, Aysen, Magallanes y Antartique Chilien et la zone métropolitaine avait le taux de croissance le plus élevé dans la création d'emplois tandis que le reste étaient en dessous de la moyenne nationale.

Mots-clés: Analyse régionale. Emploi. Chili.

Resumen: Este trabajo pretende analizar la variación regional y sectorial del empleo en Chile entre 2007 y 2009. Se objetiva comparar el rendimiento de cada región y sector, analizando los sectores y las regiones que experimentaron un crecimiento en contraste a las condiciones adversas mundiales. Para ello, se utilizó la segmentación sectorial regional del empleo publicado por el Instituto Nacional de Estadísticas de Chile, que identifican empleo en nueve sectores. Ellos son: agricultura, caza y pesca; Industria; Electricidad, gas y agua; Construcción; comercio; Transporte y comunicaciones; Servicios sociales y financieros. Para el desarrollo de este estudio se utilizó la metodología shift-share (estructuraldiferencial) una herramienta estadística que ayuda a identificar los diferentes factores relacionados a la variación del empleo.

Palabras clave: Análisis regional. Empleo. Chile.

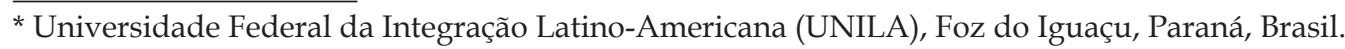




\section{INTRODUÇÃO}

A crise financeira mundial de 2008, originada no setor financeiro norte-americano, influenciou a economia real, afetando o desempenho de distintas variáveis macroeconômicas. Segundo dados do Banco Mundial (s.d.), o Produto Interno Bruto (PIB) mundial reduziu-se de US\$ 61,95 trilhões, em 2007, para US\$ 58,8 trilhões, em 2009. Essa diminuição do PIB foi verificada em várias economias, inclusive na economia chilena, que passou de US\$ 173.006.275.030 para US\$ 172.323.378, durante o mesmo período.

A preocupação com o nível de emprego durante esse período decorre das condições macroeconômica desfavoráveis ocasionadas pela crise. Conforme Oliveira e Silva (2008), o nível de emprego é uma variável dependente do comportamento geral da economia.

Segundo Ribeiro (2008) a economia chilena é considerada um caso pragmático de sucesso econômico na América Latina, a qual concilia um excelente equilíbrio da macroeconomia e uma gradual abertura comercial. Entretanto essa estratégia de crescimento econômico baseada no dinamismo exportador condiciona o país ao cenário internacional.

Conforme destaca a Agência Brasileira de Promoção de Exportação e Investimentos (APEX-BRASIL, 2010), nos últimos anos, o Chile vem sendo reconhecido por estar entre as economias mais estáveis e abertas da América Latina. Sua posição geográfica lhe favorece em relação ao comércio com países do oceano pacífico. Ao todo, o Chile possui vinte e três acordos comerciais com aproximadamente sessenta países.

Ainda, segundo a Apex-Brasil, o país mantém maior laço comercial com países do pacífico do que com seus vizinhos, isso porque o Chile "tem um histórico de conflitos com seus vizinhos de fronteira, o que explica em parte sua opção de voltar-se para o Pacífico. As principais disputas se deram com Bolívia e Peru, países que perderam parte de seus territórios após a Guerra do Pacífico" (APEX-BRASIL, 2010, p. 23).

No que tange às políticas internas, assim como outros países da América Latina, o país passou por um período conturbado de ditadura militar entre 1973 e 1990, "apesar disso, a transição democrática do país ocorreu de forma tranquila e negociada" (APEX-BRASIL, 2010, p. 22). Desde o fim desse período até fins da primeira década de 2000, o país foi governado por presidentes da "concertación", ou seja, coalizão de centro-esquerda.

Dessa forma, o objetivo geral desta pesquisa é analisar a evolução do emprego formal nas regiões chilenas no período posterior à crise econômica. Especificamente, serão estudadas as variações do emprego formal setorial para cada região chilena, comparando-as aos resultados referente à República do Chile.

Para cumprir o objetivo proposto, o presente artigo está dividido em cinco partes. Após a introdução, procura-se apresentar os aspectos econômicos da crise de 2008 e seus impactos na economia do Chile, focando a evolução da conjuntura econômica no período escolhido. Depois, busca-se explicitar a metodologia de análise shift-share. No quarto tópico do artigo, busca-se demonstrar os resultados obtidos na pesquisa. No último item, trata-se das considerações finais e encerra-se com a identificação dos setores que mais sofreram os impactos da crise, bem como apontam-se as regiões com maiores e menores participação na criação de empregos.

\section{A ECONOMIA CHILENA E A CRISE DE 2008 - CONTEXTUALIZAÇÃO}

A crise econômica, que se espalhou pelo mundo em meados de 2008 , teve sua origem e desdobramento no setor financeiro da economia norte-americana. Conforme Gontijo (2008), a origem da crise insere-se no último ciclo de construção residencial entre 2000 e 2001. Durante esse período, a economia estadunidense enfrentava uma recessão ocasionada pela bolha do mercado acionário, particularmente no setor de alta tecnologia e dos ataques terroristas de onze de setembro.

Para reaquecer a economia, o Federal Reserve optou por uma série de redução na taxa de juros da economia norte-americana. Segundo Schiwingel (2010), tais reduções geraram desequilíbrio nos Estados Unidos, dado que provocou aumento da demanda por bens duráveis e, principalmente, por imóveis, provocando uma pressão altíssima sobre seus preços.

Essas baixas taxas somadas à alta do preço das moradias são elementos que 
explicam a criação de um ciclo de crescimento baseado no consumo por endividamento, no qual os norte-americanos foram incentivados a refinanciar seus imóveis e utilizar seus recursos para o consumo e/ou pagamento de outras dívidas (SCHIWINGEL, 2010).

Dadas as condições favoráveis, decorrentes do progressivo aumento da demanda por imóveis, as instituições utilizaram, de forma mais intensa, o processo denominado securitização (NATARIO, 2009).

As instituições aglutinavam recebíveis de financiamentos imobiliário, especialmente de mercado subprime - que rendiam juros elevados, classificando seu risco com o auxílio de agências de rating. Com isso, os financiamentos hipotecários norte-americanos passaram a ser líquidos e, assim, foram distribuídos pelo sistema financeiro mundial. A securitização permitiu que o risco fosse transferido dos bancos que originavam os financiamentos para títulos lastreados em ativos, que eram absolvidos por fundos de hegde no EUA e no exterior, e para os commercial papers lastreados em ativos de bancos comerciais e de investimentos. (PORTUGAL et al., 2009 apud SCHIWNGEL, 2010, p. 37).

Entretanto, conforme Sobreira (2008), o envolvimento das agências de classificação de risco foi o principal agravante, pois estas associavam às obrigações (juros pagos pelos títulos no mercado subprime) um grau de risco muito inferior ao efetivo.

Em reação às constantes elevações da taxa de inflação ${ }^{1}$, o Federal Reserve inicia um período de aumento da taxa de juros, chegando a aproximadamente 5\% ao ano, em 2006; é a maior taxa de juros desde 2000 (RIPPEL; RIPPEL, 2008).

De acordo com Shwingel (2010, p. 38), em 2007, "iniciou o período obrigatório de ajuste ou refinanciamento dos créditos subprime [recursos financeiros destinado ao mercado subprime para financiamento dos imóveis], causando a elevação dos pagamentos a serem efetuados".

\footnotetext{
${ }^{1}$ No ano de 2005, a economia norte-americana apresentou taxa de inflação de 3,2 \%, de acordo com Banco Mundial, a maior desde 2001. Mais detalhes ver Rippel e Rippel (2008).
}

Dessa forma, as pessoas da categoria subprime, que careciam de renda fixa, ou até mesmo, que dispunham de baixas rendas não conseguiram honrar suas dívidas, devido a esse aumento de juros, havendo, em vários casos, devolução do imóvel (CARVALHO, 2008). Assim,

Quando os tomadores de hipotecas ficam inadimplentes e param de pagar os juros, aqueles investidores que compraram títulos baseados nessas hipotecas percebem que poderão não receber o retorno que esperavam. Quando essa percepção se espalha, aqueles outros investidores e instituições que compraram títulos parecidos começam a se perguntar se não é melhor se livrarem deles enquanto é tempo. Quando, porém, tentam vender esses papéis, percebem que não há muitos compradores, já que todos têm os mesmo temores. (CARVALHO, 2008, p. 19).

Consequentemente, com as altas taxas de juros somadas a um grande número de inadimplência, os bancos passaram a dificultar a concessão de empréstimos para pessoas físicas. "Confusão e medo do que estava acontecendo no sistema financeiro, levaram a uma intensa queda de confiança e, em contrapartida, a uma parada no consumo e nos investimentos" (BLANCHARD, 2011, p. 543).

Desse modo, a crise financeira afetou a economia real e países que não haviam contraído aqueles títulos securitizados. Conforme aponta Blanchard (2011), a propagação sucedeu por três vias: 1) queda das exportações para os Estados Unidos; 2) diminuição dos fluxos de capitais e 3) fator de confiança, que gerou uma queda na demanda e na produção.

Por conseguinte as consequências da crise se manifestaram de maneira divergente em cada país, conforme o grau de correlação com o exterior, bem como as políticas adotadas dado o cenário mundial desfavorável.

\subsection{Economia chilena nos anos 2000}

A República do Chile, localizada na América do Sul, possui extensa costa com o pacífico e longa fronteira pelos Andes, especificamente com Argentina, Bolívia e Peru. Além de sua extensa faixa territorial, possui territórios insulares no oceano Pacífico como 
o arquipélago Juan Fernández, Sala y Gómez, Ilhas Desventuradas e a Ilha de Páscoa, totalizando uma área de $755.838,7 \mathrm{~km}^{2}$. O território está dividido em quinze regiões, conforme divisão político-administrativa, sendo as últimas criadas em 2007 pelas leis $n^{\circ} 20174$ e 20175, respectivamente, em 5 e 11 de abril, conforme a Figura 1.

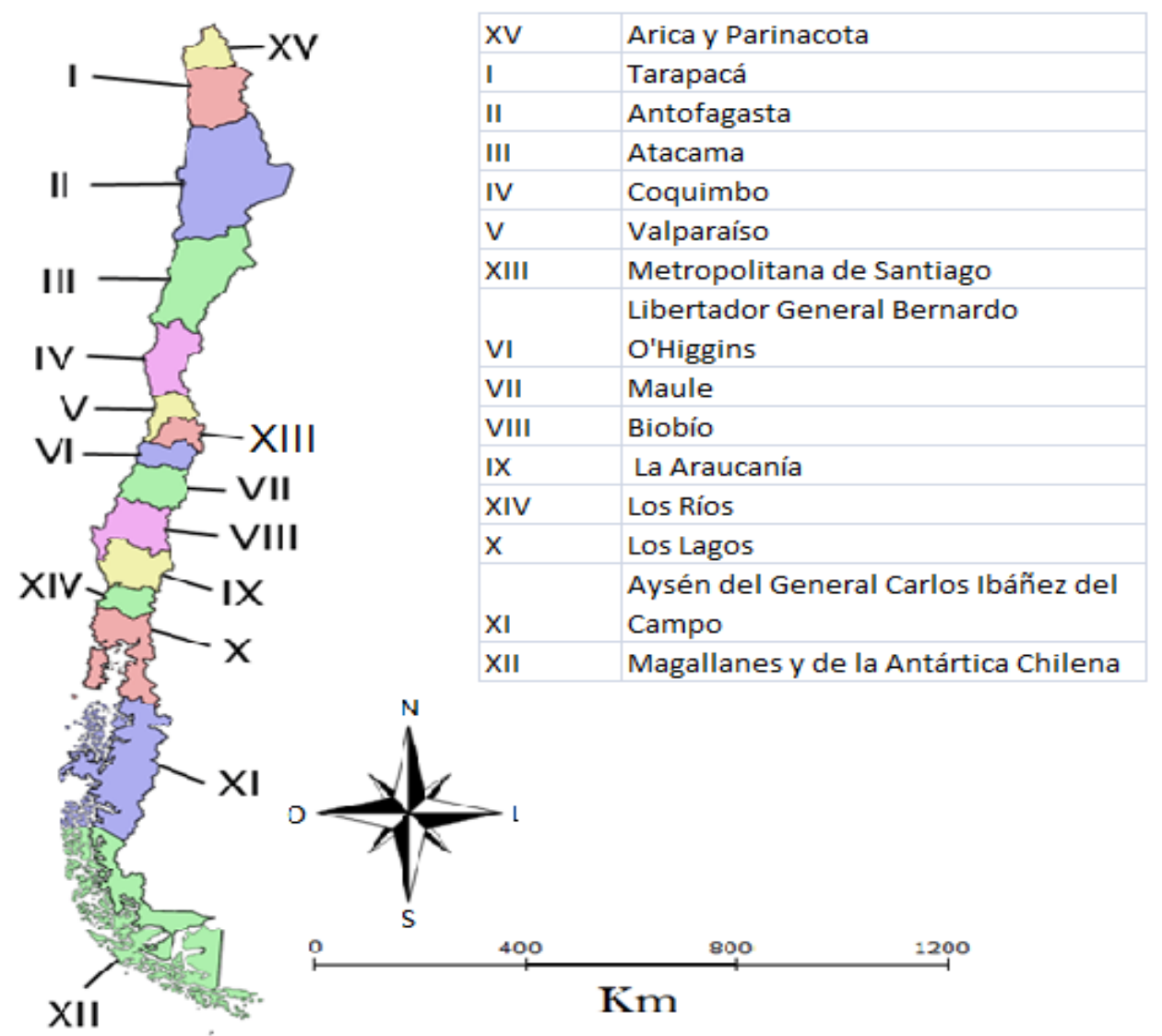

Figura 1 - Mapa regional chileno

Fonte: Elaboração própria, com base no software TerraView.

A população chilena é de aproximadamente 16 milhões de habitantes, segundo dados do censo de 2012. A capital Santiago congrega a maior parte da população, aproximadamente $40 \%$ do total, seguida das regiões de Valparaíso e Biobío.

O país se destaca por seu alto índice de alfabetização. Como destacado pelo Censo (2012), 97,8\% da população é alfabetizada. Além deste, outro destaque é o Índice de Desenvolvimento Humano (IDH) que, de acordo com dados do Banco Mundial (s.d.), foi de 0,822 em 2013, sendo o maior da América Latina.

A economia chilena é caracterizada por um elevado fluxo de comércio exterior. As exportações de bens e serviços, em 2013, representaram 33\% PIB. Além disso, o país con- centra $40 \%$ das reservas mundiais de cobre, o que o torna um dos principais exportador desse produto (BANCO MUNDIAL, s.d.)

De acordo com Sanfuentes (2010), nos anos antecedentes à crise, o governo chileno conseguiu adotar medidas que favoreceram e explicam a rápida recuperação da economia ante a crise mundial.

O país dispunha de favoráveis variáveis macroeconômicas, que foram fundamentais para que os efeitos da crise não fossem piores, tais como: 1) equilíbrio das finanças públicas; 2) saldo positivo do Fundo de Estabilização Econômica \& Social e do Fundo de Reservas de Pensão, gerados a partir dos sucessivos superávits fiscais; 3) o fato de o Estado ser um credor líquido para exterior; 4) a posse de grande quantidade de reservas internacionais; 
5) as baixas taxas de inflação que o país vinha apresentando²; e 6) a constituição de um sólido sistema financeiro (SANFLUENTES, 2010).

Ainda em 2000, sob o governo do Presidente Ricardo Lagos Escobar (2000-2006), formalizou-se uma política fiscal baseada em uma regra de balanço estrutural. De acordo com Bochi (2011, p. 17):

Essa regra baseava-se no seguinte pressuposto: se o produto efetivo alcançasse o PIB potencial (definido como uma taxa de expansão de longo prazo de $5,7 \%$ ) e o preço do cobre fosse o de equilíbrio (estimado em 92 centavos de dólar de libra), o superávit contábil do governo seria de $1 \%$ do PIB.

Através dessa medida, durante os anos de 2004-2007, com o aumento das exportações e, consequentemente, a geração de superávit, o governo criou o Fundo de Estabilização Econômica e Social (FEES) e o Fundo de
Reservas de Pensão (FRP), criados em 2006 e 2007, respectivamente.

A fim de intensificar a estratégia crescimento econômico baseado no comércio exterior, ao longo dos anos 2000, a abertura comercial cresceu gradativamente. De 2000 a 2010, foram firmados quinze acordos comerciais.

Entretanto, em 2007, "os riscos que se materializaram no cenário externo e interno complicaram o manejo macroeconômico" (BOCHI, 2011, p. 20), pela primeira vez desde 2001 a inflação superou a meta de $4 \%$. Além disso, tanto as exportações como o crescimento econômico tiveram quedas significativas.

Em 2008, com o boom da crise, agravou-se a contração da demanda agregada, seguida por uma queda da produção e do emprego. Conforme dados do Banco Central do Chile (2014), o PIB chileno passou US\$173.006.275.030, em 2007, para US\$ 172.323.378.550 em 2009. Nesse mesmo período, houve uma significativa elevação da taxa de desemprego, expressa no Gráfico 1.

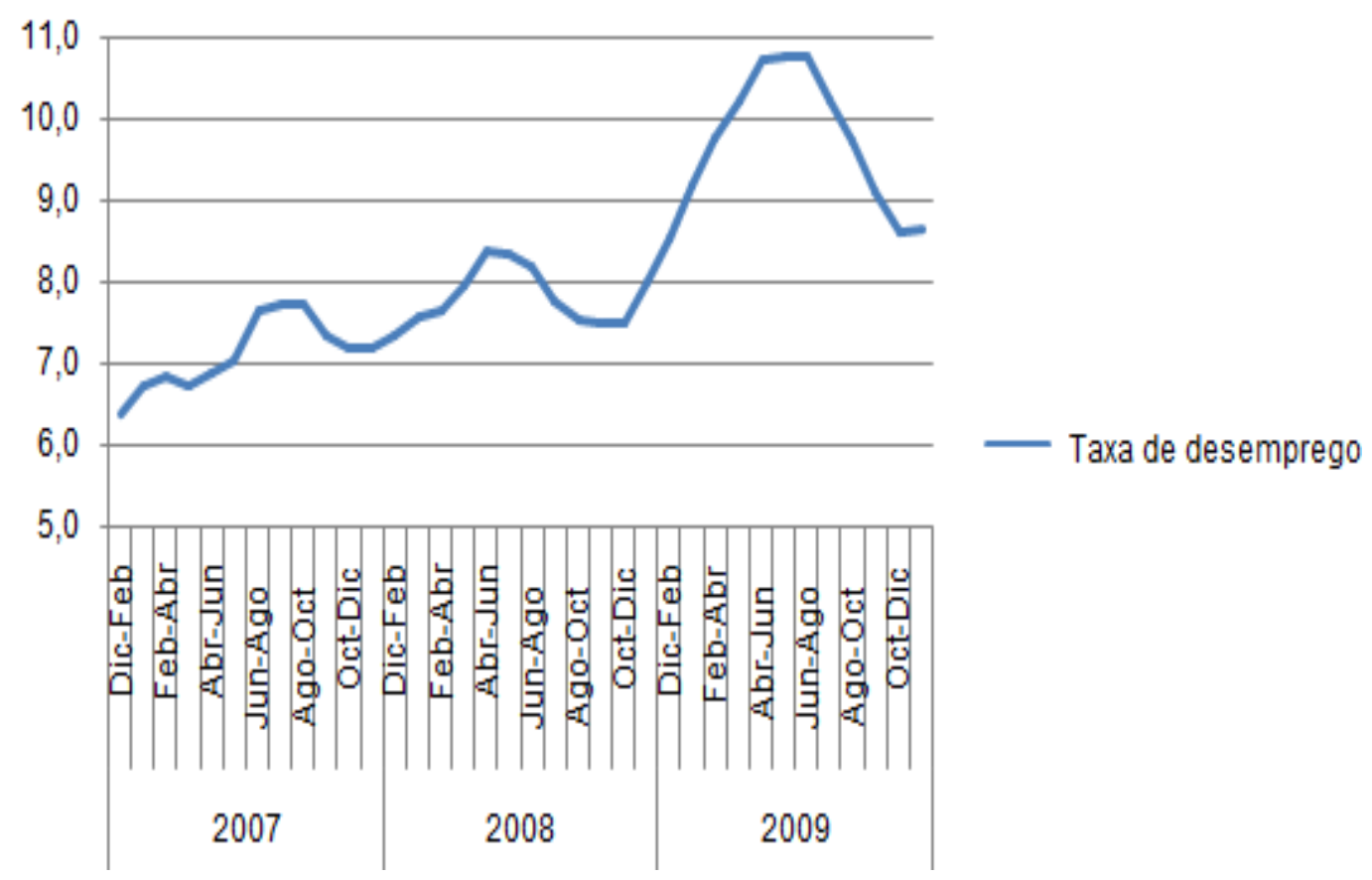

Gráfico 1 - Taxa de desemprego, expressa em milhares.

Fonte: INE (s.d.).

\footnotetext{
${ }^{2}$ Desde 2001 o Banco Central compromete-se em orientar sua política monetária de forma a manter a inflação na faixa de 2 a $4 \%$ ao ano, sem correlação direta com a taxa de crescimento do PIB (SANFLUENTES, 2010).
} 
Já as exportações, segundo Moyano (2010), decaíram fortemente desde o segundo trimestre de 2008 até o terceiro trimestre de 2009, fato correlacionado à contração mundial.

Diante desse cenário, o governo passou a adotar ações econômicas anticíclicas, dentre elas: 1) aumento da taxa de juros; 2) criação de linhas de crédito para apoiar os bancos locais; 3) entrega de bônus para as famílias vulneráveis através do programa Chile solidário e 4) Ampliação do programa Pro emprego.

No transcorrer de 2009, a economia mundial já se recuperava dos momentos de maior incerteza nos mercados financeiros internacionais. Dessa forma, "Chile experimentou um acesso relativamente fácil ao crédito externo, o que permitiu normalizar o comércio exterior e o financiamento externo

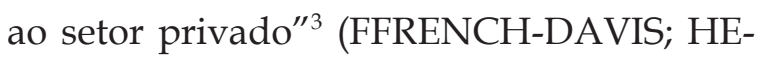
RESI, 2012, p. 17/ tradução livre).

Assim, as políticas anticíclicas adotadas pelo governo, ao longo de 2008-2009, obtiveram êxitos em 2010. Tanto o PIB como as exportações voltaram a crescer, enquanto a inflação retomou ao patamar da meta.

\section{METODOLOGIA SHIFT-SHARE}

O método de análise shift-share, também denominado Estrutural-Diferencial, é uma ferramenta de análise regional, o qual descreve o crescimento econômico de uma região no que tange aos aspectos de sua estrutura produtiva.

Conforme Simões (2005, p. 10), “o método parte da constatação empírica que há diferenças setoriais e regionais nos ritmos de crescimento entre dois períodos de tempo", tais assimetrias decorrem das singularidades de cada região, bem como das divergências setoriais na composição produtiva.

"A diferença entre o crescimento efetivo em cada região e seu crescimento hipotético (estimado utilizando-se a taxa global de crescimento) é decorrente de dois fatores: estrutural e diferencial" (OLIVEIRA; SILVA, 2008, p. 421). O fator estrutural nos permite identificar alguns setores que crescem mais rápido que

\footnotetext{
${ }^{3}$ Chile experimentó un acesso relativamente expedito al crédito externo, lo que permitió normalizar el financiamento del comercio exterior y el financiamento externo al sector privado.
}

os demais, fato decorrente das variações de demanda, produtividade e progresso tecnológico, enquanto que o fator diferencial está associado com as variações de recursos naturais, custos de transporte, especialização da mão de obra, preços de insumos e afins.

De acordo com Vale e Vasconcellos (1984), é primordial seguir um roteiro para aplicação correta da metodologia. Deve-se: 1) definir uma região de análise, averiguando o desempenho de cada microrregião que a forma; 2) escolher uma variável para análise e 3) isolar os efeitos da variável utilizada para obter o desempenho de cada componente do método.

O terceiro passo é realizado pela decomposição da variável em duas partes, componente diferencial produtiva e componente alteração proporcional ou componente estrutural produtiva.

De acordo com Silva (2002), o modelo tradicional é descrito da seguinte maneira:

$\Sigma \Delta \mathrm{X}_{\mathrm{ik}}=\Sigma\left[\mathrm{X}_{\mathrm{ik}(\mathrm{t})}-\mathrm{X}_{\mathrm{ik}(\mathrm{t}-1)}\right]=\Sigma\left[\mathrm{NX}_{\mathrm{ik}}+\mathrm{SX}_{\mathrm{ik}}+\mathrm{RX}_{\mathrm{ik}}\right]$

Onde :

- $\Delta \mathrm{X}_{\mathrm{ik}}$ representa a variação observada na variável $\mathrm{X}_{\mathrm{ik}}$;

- $X_{\mathrm{ik}(\mathrm{t})}$ representa a variável econômica $X$, medida na região $i$, no setor $k$, no período de análise $\mathrm{t}$;

- $\mathrm{NX}_{\mathrm{ik}}$ representa o componente nacional ou macrorregional;

- $\mathrm{SX}_{\mathrm{ik}}$ representa o componente estrutural;

- $\mathrm{RX}_{\mathrm{ik}}$ representa o componente regional ou diferencial.

A realização do último passo é realizada pela seguinte equação:

$$
\begin{aligned}
& \quad \mathrm{NX}_{\mathrm{ik}}=\mathrm{g}_{\mathrm{NX}} \cdot \mathrm{X}_{\mathrm{ik}(\mathrm{t}-1)} \\
& \mathrm{SX}_{\mathrm{ik}}=\left(\mathrm{g}_{\mathrm{NXK}}-\mathrm{g}_{\mathrm{NK}}\right) \cdot \mathrm{X}_{\mathrm{ik}(\mathrm{t}-1)} \\
& \mathrm{RX}_{\mathrm{ik}}=\left(\mathrm{g}_{\mathrm{ik}}-\mathrm{g}_{\mathrm{NXK}}\right) \cdot \mathrm{X}_{\mathrm{ik}(\mathrm{t}-1)} \\
& \text { sendo que: }
\end{aligned}
$$

- $\mathrm{g}_{\mathrm{NX}}$ reflete a variação percentual da variável $X$ observada em nível macrorregional;

- $\mathrm{g}_{\mathrm{NXK}}$ reflete a variação percentual da variável X observada em nível macrorregional, no setor $\mathrm{k}$;

- $\mathrm{g}_{\mathrm{ik}}$ reflete a variação percentual da variável $X$, observada na região $i$, no setor $k$. 
A análise dos resultados se dá com base nas variações obtidas no método. São elas:

- Variação Líquida Estrutural (VLE) representando o fator estrutural supracitado, e que é representado algebricamente por $S X_{\mathrm{ik}}$.

- Variação Líquida Diferencial (VLD) representando o fator diferencial ou regional, sendo simbolizado pelo componente $\mathrm{RX}_{\mathrm{ik}}$.

- Variação Líquida Total (VLT), esta é obtida pela soma da VLE e VLD.

Baseando-se nas variações apresenta- das, diversos autores analisam os resultados com o auxílio de tabelas, quadros e mapas. No presente trabalho, os resultados são expressos de acordo com as interpretações de Silva (2002), Simões (2005) e por mapas.

A Tabela 1 exemplifica as formas de análise de Silva (2002), o qual propõe a construção de gráfico sendo os resultados analisados conforme cada quadrante, e de Simões (2005), que caracteriza as regiões através de tipologias.

Tabela 1 - Guia para interpretação dos resultados

\begin{tabular}{|c|c|c|c|c|c|}
\hline VLT & VLE & VLD & Quadrantes & Tipologia & Características \\
\hline+ & + & + & I & A1 & $\begin{array}{l}\text { Região mais favorável; apresenta variações positivas nos } \\
\text { dois componentes. }\end{array}$ \\
\hline+ & + & - & II & $\mathrm{A} 2$ & $\begin{array}{l}\text { Apesar de apresentar variação positiva em sua totali- } \\
\text { dade, seu componente diferencial exibe variação nega- } \\
\text { tiva, é dizer, não apresenta vantagens locacionais tão } \\
\text { grande. Entretanto conta em sua estrutura com setores } \\
\text { dinâmicos que são capazes de suprimir essas desvanta- } \\
\text { gens. }\end{array}$ \\
\hline+ & - & + & IV & A3 & $\begin{array}{l}\text { Nessa tipologia ocorre o oposto da A2. Aqui as vanta- } \\
\text { gens locacionais suprem as desvantagens estruturais. }\end{array}$ \\
\hline- & - & + & IV & B1 & $\begin{array}{l}\text { Exibe a mesma configuração das regiões que configuram } \\
\text { em A3, porém suas vantagens locacionais não suprem as } \\
\text { desvantagens estruturais. }\end{array}$ \\
\hline - & + & - & II & B2 & $\begin{array}{l}\text { Região com um perfil de especialização favorável, mas } \\
\text { apresenta problemas em termos de vantagens competiti- } \\
\text { vas especificas, resultando numa variação total negativa. }\end{array}$ \\
\hline- & - & - & III & B3 & $\begin{array}{l}\text { Região mais desfavorável; apresenta desvantagens tanto } \\
\text { no componente estrutural quanto locacional. }\end{array}$ \\
\hline
\end{tabular}

Fonte: Elaboração própria com base em Silva (2002) e Simões (2005).

\section{BASE DE DADOS E RESULTADOS}

Os dados utilizados no presente artigo foram obtidos por meio da website do Instituto Nacional de Estatística (INE) do Chile. O INE é responsável pela elaboração e divulgação das principais estatísticas regionais e nacional.

A divisão setorial do emprego segue a segmentação elaborada pelo instituto. Desse modo, no presente artigo, utilizam-se nove setores. São eles: Agricultura, Caça e pesca; Mineração; Indústria; Eletricidade, Gás e água; Construção; Comércio; Transporte e comunicação; Serviços financeiros e Serviços sociais.

\subsection{Variação do emprego no Chile confor- me análise shift-share}

O período 2007-2009 foi marcado por baixo crescimento do emprego formal no Chile, a uma taxa de $2,60 \%$ ao ano, representando um aumento absoluto de 165.930 de novos empregos, conforme mostra a Tabela 2.

Com relação ao setor de serviços sociais, cabe destacar que esse crescimento deve-se, em grande medida, à ação governamental. Durante esse período, programas como o Pro-empleo (especificamente, a área de investimento na comunidade) e o Programa Serviços Comunitários, contaram com um maior inves- 
timento se comparado com anos anteriores (SUBSECRETARIA DE TRABALHO DO CHILE apud MUGA, 2010).

Tabela 2 - Número de empregos no Chile, variação percentual e absoluta por setor - 2007/2009

\begin{tabular}{lcccc} 
& \multicolumn{2}{c}{$\begin{array}{c}\text { Emprego Formal } \\
\text { Setor }\end{array}$} & \multicolumn{1}{c}{ (em milhares) } & \multicolumn{2}{c}{ Variação } \\
& $\mathbf{2 0 0 7}$ & $\mathbf{2 0 0 9}$ & $\mathbf{0}$ & $\begin{array}{c}\text { Absoluta } \\
\text { (em milhares) }\end{array}$ \\
\hline Agricultura, caça e pesca & 713,64 & 693,38 & $-2,84$ & $-20,26$ \\
\hline Mineração & 96,22 & 95,5 & $-0,75$ & $-0,72$ \\
\hline Indústria & 856,37 & 853,2 & $-0,37$ & $-3,17$ \\
\hline Eletricidade, Gás e água & 45,24 & 31,83 & $-29,64$ & $-13,41$ \\
\hline Construção & 540,59 & 533,39 & $-1,33$ & $-7,2$ \\
\hline Comércio & 1268,93 & 1322,92 & 4,25 & 53,99 \\
\hline Transporte e comunicação & 509,75 & 514,56 & 0,94 & 4,81 \\
\hline Serviços financeiros & 567,05 & 644,84 & 13,72 & 77,79 \\
\hline Serviços sociais & 1773,91 & 1848,01 & 4,18 & 74,1 \\
\hline Total & 6371,7 & 6537,63 & 2,60 & 165,93
\end{tabular}

Fonte: Resultados da pesquisa.

No caso da agricultura, caça e pesca, as dificuldades apareceram nos anos antecedentes à crise. De acordo com Muga (2010), especificamente no setor da agricultura, as grandes dificuldades desde 2006 decorrem das geadas, que ocasionaram queda tanto do produto desse setor quanto dos investimentos, o que se agravou no período da crise.

No que tange ao setor de construção, apesar dos incentivos governamentais, a dificuldade de se conseguir créditos somada aos baixos investimentos privados foram responsáveis pela queda do emprego nesse setor. Em relação ao desempenho regional, a Tabela 3 apresenta a variação percentual e absoluta de cada região, assim como a nacional. Os dados estão expressos em milhares de pessoas.

Tabela 3 - Variação do emprego nas regiões chilenas - 2007/2009.

\begin{tabular}{lcccc} 
& \multicolumn{2}{c}{ EMPREGOS FORMAIS } & \multicolumn{2}{c}{ VARIAÇÃO } \\
& $\mathbf{2 0 0 7}$ & $\mathbf{2 0 0 9}$ & $\mathbf{\%}$ & $\begin{array}{c}\text { ABSOLUTA } \\
\text { (Milhares) }\end{array}$ \\
CHILE & 6371,7 & 6537,63 & 2,60 & 165,93 \\
Tarapacá (I) & 189,4 & 208,23 & 9,94 & 18,83 \\
Antofagasta (II) & 215,72 & 213,84 & $-0,87$ & $-1,88$ \\
\hline Atacama (III) & 112,43 & 112,11 & $-0,28$ & $-0,32$ \\
Coquimbo (IV) & 237,71 & 250,29 & 5,29 & 12,58 \\
Valparaíso (V) & 632,04 & 643,23 & 1,77 & 11,19 \\
O'Higgins (VI) & 306,84 & 300,52 & $-2,06$ & $-6,32$ \\
Maule (VII) & 340,76 & 343,34 & 0,76 & 2,58 \\
BioBío (VIII) & 682,01 & 699,89 & 2,62 & 17,88 \\
La Araucanía (IX) & 333,32 & 352,5 & 5,75 & 19,18 \\
Los Lagos (X) & 455,96 & 449,02 & $-1,52$ & $-6,94$ \\
Aysen (XI) & 45,07 & 47,39 & 5,15 & 2,32 \\
Magallanes y la Antártica Chilena (XII) & 64,7 & 66,78 & 3,21 & 2,08 \\
Região Metropolitana (XIII) & 2755,74 & 2850,49 & 3,438278 & 94,75
\end{tabular}

Fonte: Resultados da pesquisa. 
Das regiões em análise, seis obtiveram taxa de crescimento inferior à taxa de crescimento nacional. São elas as regiões: Antofagasta, Atacama, Valparaíso, O'Higgins, Maule e Los Lagos, com - $0,87 \%$, $-0,28 \%, 1,77 \%$, $-2,06 \%, 0,76 \%$ e $-1,52 \%$, respectivamente.

No outro extremo, merecem destaque as regiões de Tarapacá, Coquimbo, La Aracanía e Aysen, que apresentaram taxas acima de 5\%. As regiões de Biobío, Magallanes y la Antártica Chilena e a Região Metropolitana também tiveram crescimento superior à taxa nacional.

Dentre todas as regiões, quatro obtiveram variação absoluta negativa, é dizer, houve uma diminuição do número total de emprego. Foram elas: Antofagasta, Atacama, O'Higgins e Los lagos. As duas últimas são os casos mais preocupantes, nas quais a diminuição foi superior a seis mil empregos.

\subsection{Resultados da análise shift-share}

Os resultados estão compreendidos em gráfico e tabelas, seguindo a análise de Silva (2002) e Simões (2005), os quais demonstram os resultados regionais, enquanto a análise setorial está disposta na forma de mapa, através da utilização do software livre Terra View.

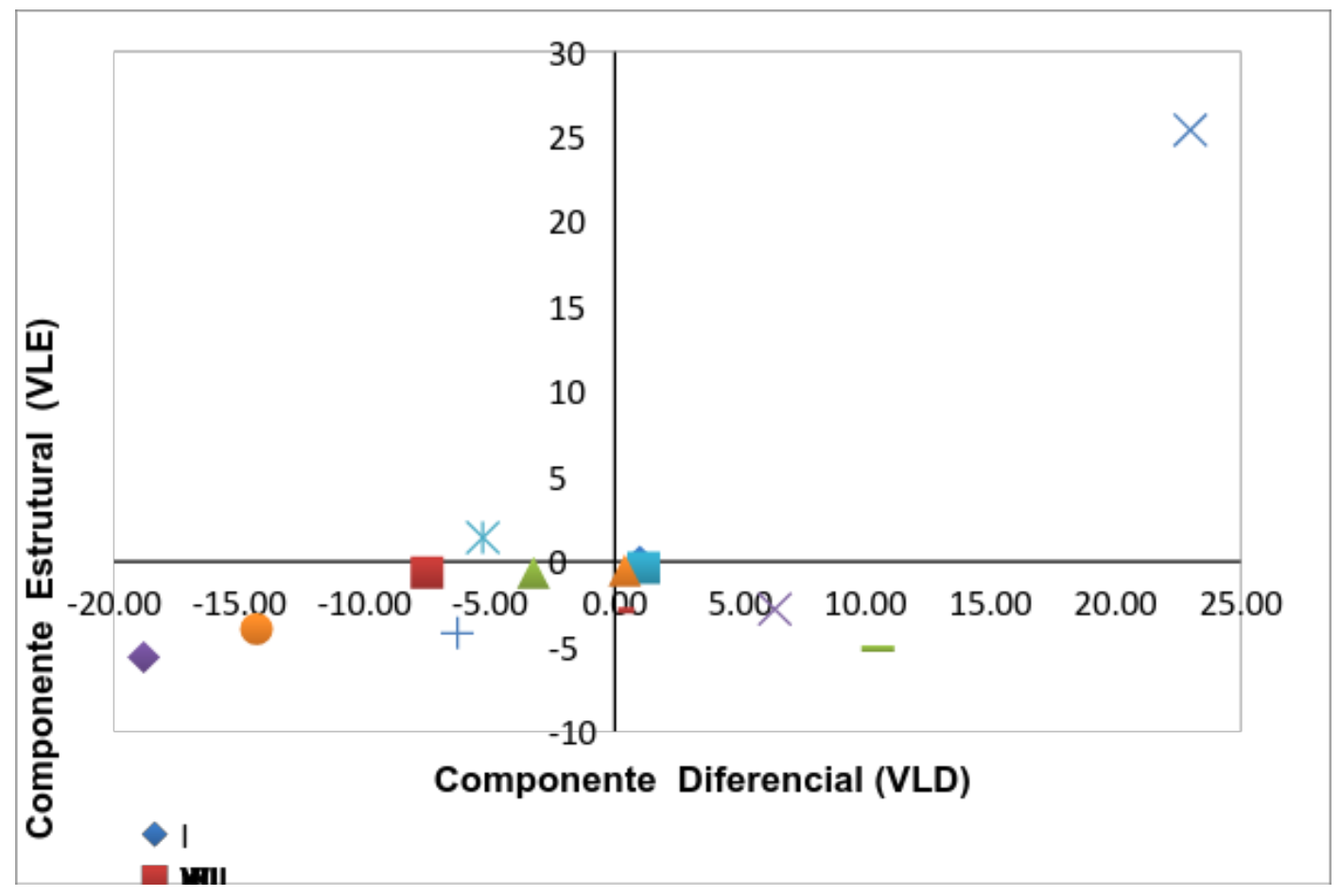

Figura 2 - Classificação shift-share por quadrantes.

Fonte: Resultados da pesquisa

A Figura 2 mostra os resultados tipológicos, baseado em Simões (2005). As regiões classificadas em A são as que apresentam crescimento acima da taxa nacional, ou seja, com VLT positiva. Por outro lado, as que cresceram a taxas menores do que a taxa nacional são as classificadas em B. Há ainda uma subdivisão que as classificam em A1, A2 e A3; B1, B2 e B3, indicando se o desempenho da região é explicado tanto pelo componente regional quanto pelo componente diferencial.
Os resultados da pesquisa indicam que apenas as regiões de Tarapacá e a região metropolitana apresentaram variações positivas tanto no componente estrutural como no diferencial, e consequentemente, sua VLT também é positiva. Regiões com essas características são classificadas em A1.

Já dentre as classificadas em A3 estão Coquimbo, La Araucanía e Aysén del General Carlos Ibáñez del Campo. Esse grupo caracteriza-se por obter variação líquida total positiva, porém, ao mesmo tempo, desvantagens 
estruturais e vantagens locacionais. Vale menção de que o oposto ocorre com as classificadas em A2, entretanto, na presente pesquisa, nenhuma região obteve essa classificação.

No outro extremo, estão as regiões classificadas em B, ou seja, que possuem VLT negativa. Dentre as regiões analisadas, cinco estão classificadas em B3, o que significa que essas regiões, além de apresentarem VLT negativa, exibem também desvantagens estruturais e diferenciais. Dentre as regiões estão: Antofagasta, Atacama, O’Higgins, Maule e Los lagos.

As regiões de BioBío e Magallanes y Antártica Chilena estão no grupo B1, regiões que apresentam desvantagens estruturais e vantagens locacionais.

Por fim, Valparaíso, única região no grupo B2, apresenta vantagens estruturais, porém as desvantagens locacionais são maiores, resultando, dessa forma, em VLT negativa.

A Figura 3 apresenta os setores que obtiveram a melhor VLT em cada região.
Nota-se que houve uma grande diversificação setorial, entretanto destaca-se o setor de serviços sociais. Em relação a componente diferencial (Figura 3.b), assim como a VLT, observa-se uma grande variação de setores. É importante atentar que as regiões que tiveram o setor de serviços sociais em evidência na VLT, majoritariamente, foram as mesmas em que esse setor se evidenciou na componente diferencial.

Com relação à componente estrutural, o setor financeiro apresentou a maior variação em praticamente todas as regiões. Esse resultado se deve à solidez do sistema financeiro chileno, ao alto nível de capitalização e ao excelente sistema de avaliação de risco. "Chile é o país onde os bancos têm feito mais reservas durante a crise" (ALARCÓN, 2010, p. 125; tradução livre). Outro fator explicativo aos resultados da VLE, em grande medida, é decorrente do baixo desempenho dos setores dinâmicos, dada a grande dificuldade que tiveram no período da crise.
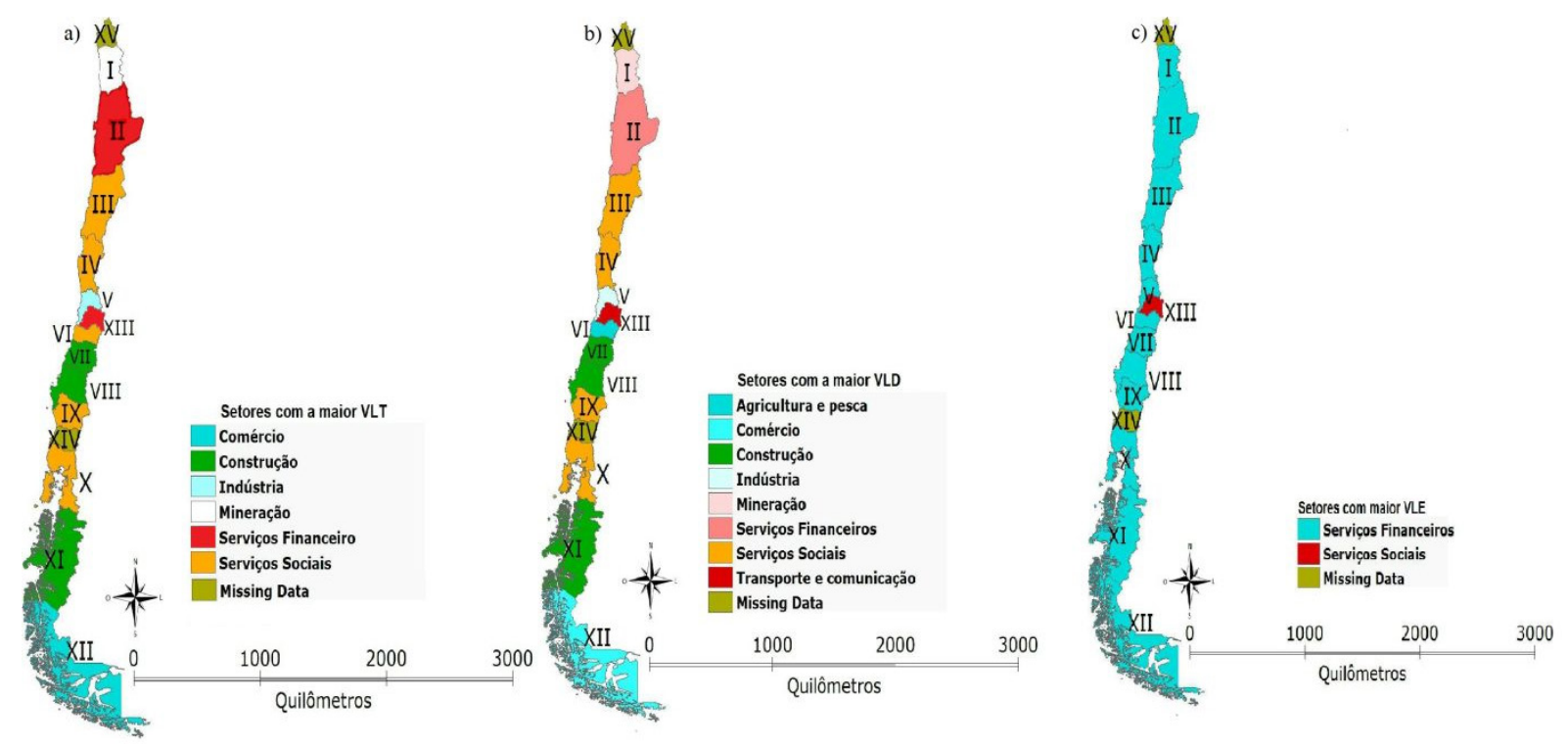

Figura 3 - Classificação tipológica com base na análise shift-share

Fonte: Resultados da pesquisa.

\section{CONSIDERAÇÕES FINAIS}

Em face da conjuntura internacional no período de crise econômica mundial e seus impactos nas variáveis econômicas dos países, o presente trabalho estudou a variação setorial-regional do emprego no Chile com uso da metodologia de análise shift-share. Aqui, cabe ressaltar que, embora o Chile tenha se destacado ao longo dos anos 2000, por apresentar uma elevada taxa de crescimento econômico somada a um excelente equilíbrio macroeconômico, observou-se que a crise freou o ritmo de crescimento econômico do 
país, afetando o nível de emprego em vários setores e regiões.Os resultados da pesquisa permitem concluir que a crise econômica de 2008 afetou o comportamento dos principais setores exportadores do Chile, notadamente os setores de mineração e agricultura, caça e pesca, que se defrontaram com a falta de demanda externa, o que ocasionou no desemprego de milhares de pessoas nas regiões onde essas atividades predominam.Ante aos problemas decorrentes da crise econômica mundial, o governo chileno utilizou os fundos criados em meados dos anos 2000 para incentivar setores relacionados ao mercado interno, principalmente o setor de serviços sociais.Não obstante isso, a aplicação da metodologia de análise shift-share explicitou a grande participação da Região Metropolitana na criação de empregos, que é responsável por mais da metade dos empregos gerados no país durante o período em análise. Do mesmo modo, identificou as regiões que tiveram os piores desempenhos diante da desfavorável conjuntura e que merecem uma atenção maior do governo chileno: Antofagasta, Atacama, O'Higgins e Los lagos.

\section{REFERÊNCIAS}

AGÊNCIA BRASILEIRA DE PROMOÇÃO DE EXPORTAÇÃO E INVESTIMENTOS (APEX-BRASIL). Perfil - País Chile. 2010. Disponível em: <http://www2.apexbrasil.com.br/media/estudo/ chile_17102012162336.pdf>. Acesso em: 15 out. 2014.

ALARCÓN, A. Impactos de la crisis internacional en el sector financeiro de chile. In: LAVALLE, P. L. (Org.). Impactos de la crisis internacional sobre la economía chilena. Santiago: Lom Ediciones; Fundación Konrad Adenauer, 2010. Cap. 6, p. 115-129.

BANCO MUNDIAL. Countries. [s.d.]. Disponível em: <www.worldbank.org>. Acesso em: 3 nov. 2014.

BLANCHARD, O. Macroeconomia. 5. ed. São Paulo: PearsonPretince Hall, 2011.

BOCHI, I. As repercussões econômicas da elevação dos preços das commodities internacionais sobre a economia chilena. 2011. 58 f. Trabalho de Conclusão de Curso (Graduação em Ciências Econômicas) - Departamento de Ciências Econômicas, Universidade Federal do Rio Grande do Sul, Porto Alegre, RS.

CARVALHO, F. J. C. Entendendo a Recente Crise Financeira Global. In: ASSOCIAÇÃO KEYNESIANA BRASILEIRA (AKB). Dossiê da Crise. [s.l.: s.n.], 2008.

CENSO. Productos Estadísticos. 2012. Disponível em: <http://www.ine.cl/>. Acesso em: 5 mar. 2014.

FFRENCH-DAVIS, R.; HERESI, R. La economía chilena frente a la crisis financiera: respustas contra-cíclicas y desafios pendientes. In: LEÓN, J. L. (Org.). La gran recesión: Respuestas en las Américas y Asia del Pacífico. México: [s.n.], 2012.

GONTIJO, C. Raízes da crise financeiro dos derivativos subprime. Belo Horizonte, MG: UFMG/Cedeplar, 2008.

INSTITUTO NACIONAL DE ESTATÍSTICA - INE. Productos estadísticos. [s.d.]. Disponível em: <www.ine.cl>. Acesso em: 23 nov. 2014.

MOYANO, E. Impactos de la crisis internacional en el sector exportador de chile. In: LAVALLE, P. L. (Org.). Impactos de la crisis internacional sobre la economía chilena. Santiago: Lom Ediciones; Fundación Konrad Adenauer, 2010. Cap. 7, p. 129-151.

MUGA, R. Impactos de la crisis internacional sobre los sectores produtivos de chile. In: LAVALLE, P. L. (Org.). Impactos de la crisis internacional sobre la economía chilena. Santiago: Lom Ediciones; Fundación Konrad Adenauer, 2010. Cap. 5, p. 95-114.

NATARIO, T. N. Uma análise sobre as origens e impactos da crise do sistema imobiliário norte-americano - as hipotecas subprime. 2009. 66 f. Trabalho de Conclusão de Curso (Graduação em Ciências Econômicas) - Universidade Federal de Santa Catarina, Florianópolis, SC.

OLIVEIRA, G. B.; SILVA, M. A. de O. de. Análise Shif-Share: um estudo sobre emprego nas regiões do Brasil nos anos de 2002 e 2003. Caderno de Iniciação Científica, Curitiba, PR, n. 9, p. 419-430, 2008.

RIBEIRO, T. M. Exportações e crescimento: um teste de causalidade para o caso chileno. 2008. 107 f. Dissertação (Mestrado em Economia Política) - Pontifícia Universidade Católica de São Paulo, São Paulo.

RIPPEL, R.; RIPPEL, V. C. L. Considerações a respeito das origens, dos acontecimentos e das conseqüências da crise econômica mundial atual. Informe Gepec, v. 12, n. 2, 2008.

SANFLUENTES, A. Capacidad de respuesta de la economía chilena ante los efectos de la crisis internacional. In: LAVALLE, P. L. (Org.). Impactos de la crisis internacional sobre la economía chilena. Santiago: Lom Ediciones; Fundación Konrad Adenauer, 2010. Cap. 4, p. 81-94.

SCHWINGEL,G. Preferência pela liquidez dos bancos durante a crise do subprime. 2010. 85 f. Monografia (Especialização em Administração) - Escola de Administração, Universidade Federal do Rio Grande do Sul, Porto Alegre, RS.

SILVA, J. C. C. A análise de componentes de variação (shift-share). In: COSTA, J. S. (Org.). Compendio de economia regional. Coimbra, Portugal: APDR, 2002. Cap. 24, p. 803-813.

SIMÕES, R. Métodos de análise regional e urbana: diagnóstico aplicado ao planejamento. Belo Horizonte: Cedeplar/UFMG, 2005.

SOBREIRA, R. Os derivativos e a crise de crédito. In: ASSOCIAÇÃO KEYNESIANA BRASILEIRA (AKB). Dossiê da Crise. [S.1.: s.n.], 2008.

VALE E VASCONCELOS, A. Análise e Alteração Proporcional (Shift - Share). In: Economia urbana. Porto, Portugal: Rés-editora, 1984. Cap. 8, p. 211-239. 